\title{
PROPOSTA DE UM MODELO DE GESTÃO DE CONTEÚDOS NOS \\ SOCIAL MEDIA: OS ESTUDOS DE CASOS DAS STARTUPS
}

\author{
PROPOSAL FOR A MANAGEMENT CONTENT MODEL IN SOCIAL \\ MEDIA: THE CASE STUDIES OF STARTUPS
}

PROPUESTA DE UN MODELO DE GESTIÓN DE CONTENIDOS EN LOS MEDIOS SOCIALES: LOS CASOS DE LAS STARTUPS

Ana Sofia Castilho Mestranda, Universidade de Aveiro anasofiacastilho@ua.pt

Maria João Antunes Doutora, Universidade de Aveiro mariajoao@ua.pt

\section{Resumo}

O estudo apresentado tem como base uma análise à presença nos social media de quinze startups portuguesas (consideradas as mais dinâmicas nos novos media), com negócios business to business (B2B) nas áreas das Tecnologias de Informação e Comunicação, Media e Design. Constata-se que contrariamente ao que seria de prever, para empresas que operam nesta área de atividade, a sua dinâmica nos novos media é reduzida. O estudo aqui apresentado pretende servir de base à criação de um modelo de gestão de conteúdos a empregar nos social media, de forma a ser adotado em empresas startups (com negócios B2B), com o intuito de captar novos stakeholders.

Palavras-chave: Conteúdos web. Social media. Startups. 


\begin{abstract}
This paper focus on an analysis of the presence in the social media of fifty portuguese startups (considered the most dynamic in the new media), in the business-to-business (B2B) area, in the fileds of Information and Communication Technologies, Media and Design. Contrary to what would be expected for organizations operating in this area, their present little activity in the new media. This study intended to constitute a basis for creating a content management model to be used in social media, in order to be adopted in startups (with a B2B approch) to attract new stakeholders.
\end{abstract}

Keywords: Social media. Startups. Web content.

\title{
Resumen
}

El estudio presentado se basa en un análisis de los social media en la presencia de quince startups portuguesas (consideradas las más dinámicas de los nuevos medios), negocios business-to-business (B2B) en las áreas de Tecnologías de Información y Comunicación, Medios de Comunicación y Diseño. Segun parece, contrariamente a lo que cabría esperar, para las empresas que operan en este sector de actividad, su dinámica en los social media es mínima. El estudio que aquí presentado tiene como objectivo servir de base para la creación de un modelo de gestión de contenidos, para su uso en las redes sociales, con el fin de que se adopten nuevas empresas B2B, con el fin de atraer a nuevos grupos de interés.

Palabras clave: Contenido web. Social media. Startups.

\section{INTRODUÇÃO}

Os social media enquadram-se na filosofia web 2.0 que Tim O'Reilly designa como a rede como plataforma digital, onde todos os dispositivos estão ligados e, onde cada utilizador controla os seus próprios dados (O'REILLY, 2007, p. 17). Com o aparecimento da web 2.0 o feedback torna-se ainda mais facilitado, são criados novos conceitos e adaptados outros existentes, nomeadamente, social media, marketing digital, engagement, return on investment (ROI), conteúdos web, entre outros. O utilizador passa a ser 
considerado como prosumer $^{1}$, isto é, continua a ser consumidor de informação, mas passa agora a poder ser também produtor dessa mesma informação.

Muitos são os estudos desenvolvidos e muitos foram e são, os benefícios que as empresas têm retirado dos Sites de Redes Sociais (ou Social Networking Sites - SNS, termo também associado à web 2.0), especialmente as que se encontram na área de negócio Business-to-Consumer (B2C). Contudo, este tema não deixa de ser relativamente recente e muito existe ainda por investigar. Segundo os autores Rodriguez, Peterson e Krishnan, os social media facilitam o feedback, permitindo às empresas melhorar as suas decisões de acordo com a opinião dos consumidores, de forma a criarem melhores soluções (RODRIGUEZ; PETERSON; KRISHNAN, 2012, p. 365 - 369). Desta forma, os autores indicam que no que concerne à área Business-to-Business (B2B), os social media ainda se encontram numa fase embrionária, pois poucas são as empresas que os utilizam no processo de vendas, angariação de novos compradores, ou mesmo no desenvolvimento de novas relações com clientes (RODRIGUEZ et al., 2012, p. 365 - 369).

Entende-se por Business-to-Business (B2B) empresas que não sejam consumidoras finais, que lidam habitualmente com outras empresas suas clientes e que por norma, obtêm bens ou serviços que usam para produção de outros bens e/ou serviços. Geralmente estas empresas distinguem-se das Business-to-Consumer (B2C) pela sua natureza, complexidade de produtos ou serviços e uma relação com os stakeholders mais duradoura (CARVALHO, 2010, p. 105 - 109).

Nesta investigação foram analisadas empresas portuguesas, mais precisamente startups que têm como área de negócio as Tecnologias de Informação e Comunicação (TIC), Media, Comunicação e Design, de forma a que haja uma melhor percepção do comportamento destas empresas nos social media.

Este artigo organiza-se em três secções: revisão de literatura e descrição da análise dos resultados obtidos através do estudo. Por fim, apresentam-se as conclusões e perspectivas de trabalho futuro.

\footnotetext{
${ }^{1}$ Prosumer, termo inspirado no livro "A Terceira Vaga" de Alvin Toffler, onde o autor define pro-sumidor.
} 


\section{ENQUADRAMENTO TEÓRICO}

No contexto português existe um número diminuto de empresas que conseguem confiar e apostar nos social media, tendo como principal intuito angariar novos stakeholders e melhorar o respetivo processo de vendas (RODRIGUEZ et al., 2012, p. 365 - 369).

\subsection{Os social media e a gestão de conteúdos}

Embora não exista uma definição única, tende a considerar-se os social media enquanto ferramentas que integram a tecnologia, a interação social e a "construção de palavras e imagens" (ANVIL MEDIA INC, 2010, p. 1), usados por pessoas ou empresas para difundir o conteúdo, que permitem a construção, a partilha e a discussão de informação entre utilizadores e transformam os leitores de conteúdos também em editores de conteúdos.

Segundo Berthon, Pitt, Plangger e Shapiro, os social media vieram facilitar a interação entre indivíduos e organizações, pois permitem compreender os seus comportamentos e os conteúdos que são disseminados na rede. Os autores referem que os social media são uma tecnologia da web 2.0, que ajuda a converter os monólogos online (onde a comunicação era de um para muitos) em diálogos (de muitos para muitos). Referem ainda que, por norma, os social media são altamente acessíveis e escaláveis, isto é, podem ser usados com facilidade por uma grande massa de utilizadores (BERTHON et al., 2012, p. 263).

Quanto aos autores Kaplan e Haenlein referem os social media como,

"(...) a group of Internet-based applications that build on the ideological and technological foundations of Web 2.0, and that allow the creation and exchange of user-generated content" (KAPLAN; HAENLEIN, 2010, p. $61)$.

No que diz respeito às áreas $\mathrm{B} 2 \mathrm{~B}$ e B2C, as empresas têm como principal intuito que o conteúdo partilhado passe para além da plataforma online, e que gere uma ação de compra de serviço ou produto, ou o simples ato de expressar a opinião sobre a organização (SOUSA; AZEVEDO, 2010, p. 2).

Os social media usam diversos tipos de conteúdos, nomeadamente texto, imagens, áudio e vídeo, sendo que cada plataforma web utiliza um ou mais tipos de conteúdos. Por exemplo, os sites de redes sociais, caracterizam-se de um modo geral, como espaços onde 
os utilizadores se podem expressar e dar visibilidade à sua rede de relações.

Genericamente designa-se por redes sociais, plataformas como: Facebook, Linkedin, Pinterest ou Myspace, embora na realidade deveríamos chamar-lhes Social Network Sites (SNS) ou Sites de Redes Sociais, pois são plataformas que servem de suporte a uma rede ${ }^{2}$ social online, onde se criam e desenvolvem laços sociais (SOUZA; GOMES, 2010, p. 4 5). Assim, os SNS são plataformas que surgem como um meio de comunicação, onde os utilizadores podem interagir uns com os outros e a comunicação é feita de uma perspetiva colaborativa (MOTA, 2011, p. 5 - 6).

Em relação ao word-of-mouth, este método é considerado uma das formas mais eficazes de marketing, pois os consumidores de um modo geral, confiam mais nas opiniões e recomendações de amigos e conhecidos (laços fortes), do que na de estranhos (laços latentes ou laços fracos). Os social media vieram de certa forma expandir a área do marketing word-to-mouth surgindo assim o conceito de Electronic Word-of-Mouth (eWOM) que, de acordo com as características dos SNS, permitem e facilitam a comunicação de uma forma mais rápida entre utilizadores, conseguindo desta forma alcançar um maior número de indivíduos.

Segundo Zhang, Jansen e Chrowdhury (2011, p. 171 - 173), o Twitter consegue ser uma das melhores plataformas de social media a ser usado no marketing eWOM. Este permite às empresas participarem ativamente na comunicação boca a boca on-line, possibilitando que haja um maior envolvimento entre a marca e os consumidores e onde os autores afirmam que a comunicação eWOM tem uma grande influência nas organizações e na confiança online da marca. Ainda assim, os empresários necessitam de considerar as mensagens eWOM no momento de desenvolvimento e gestão do seu plano estratégico de comunicação (ZHANG; JANSEN; CHOWDHURY, 2011, p. 171 - 173). Jansen, Zhang, Sobel e Chowdury (2009, p. 2172 - 2177) referem também que de acordo com um dos estudos efectuados por estes, onde foram selecionadas cinquenta marcas, sendo analisados os microblogs que referenciavam essas marcas ao longo de treze semanas consecutivas, um quinto de todos os tweets contêm o nome de uma empresa, produto ou serviço e que um quinto desses tweets expressa um tipo de sentimento, onde mais de metade são positivos e

\footnotetext{
${ }^{2}$ Por rede, entende-se um "grupo de individuos, de forma agrupada ou individual, que se relacionam uns com os outros, com um fim especifico, caracterizando-se pela existência de fluxos de informação. As redes podem ter muitos ou poucos atores e uma ou mais classes de relações entre pares de atores" (ALEJANDRO; NORMAN, 2005, p. 35).
} 
um terço são negativos. Desta forma, concluíram que o Twitter é uma plataforma rica para as empresas explorarem, como parte integrante da estratégia online da marca, permitindolhes obter uma fonte de inteligência coletiva (JANSEN et al., 2009, p. 2172 - 2177).

\section{2 As startups nas áreas B2B e o engagement nos social media}

Michaelidou, Siamagka e Christodoulides (2011, p. 1153) mencionam que as empresas B2B devem usar os social media e especificamente os SNS, como por exemplo o Facebook ou o Linkedin, de forma a melhor comunicarem com os seus consumidores e fornecedores, com o intuito de construírem laços mais fortes e relações de confiança, podendo desta forma, identificar também mais facilmente potenciais parceiros (MICHAELIDOU; SIAMAGKA; CHRISTODOULIDES, 2011, p. 1153).

Mas não é o que tem acontecido no caso português, onde uma grande maioria das startups tem uma dinâmica muito baixa, em termos de uso e partilha de conteúdos e interação com os utilizadores nos social media. Segundo Karkkainen, Jussila e Vaisanen (2010, p. 234), a falta de compreensão das possibilidades que os social media podem trazer à inovação da empresa; as dificuldades em avaliar os ganhos financeiros que os social media podem retornar; as dificuldades em adotar novos modelos e práticas necessárias para essa adoção; assim como, a falta de casos de sucesso que usem os social media, são referidas como as principais razões para a relutância da sua adoção por parte das empresas, principalmente as que se encontram na área B2B (KARKKAINEN; JUSSILA; VAISANEN, 2010, p. 234).

Qualquer empresa, ao adotar o uso de social media no seu negócio, deverá inicialmente definir quais os objetivos ao operar nesse ambiente, tendo esses objetivos que estar alinhados com os objetivos da própria empresa, de forma a escolherem os social media que melhor de adequam e facilitam as necessidades desta (JUSSILA; KARKKAINEN; LEINO, 2011, p. 167). O desafio é acompanhar a elevada dinâmica e a rápida evolução dos social media, algo que pode ser difícil de aceitar para os gestores das empresas (JUSSILA et al., 2011, p. 170).

Relembrando que este estudo recai em startups ligadas à área das Tecnologias de Informação e Comunicação, Media e Design, sabe-se que as startups são por norma empresas relativamente novas que têm como base, ideias inovadoras e tecnológicas, tendo 
no seu início custos reduzidos e sendo profundamente escaláveis, quando o projeto é de sucesso. Para alcançar um maior êxito, estas empresas deverão desenvolver competências de forma a reagir facilmente à mudança e adquirir uma equipa multidisciplinar. No estudo desenvolvido por Michaelidou, Siamagka e Christodoulides (2011, p. 1154), os autores referem que as empresas mais pequenas são por norma mais recetivas à inovação e às novas tecnologias, sendo esperado que sejam mais facilmente abertas à mudança e à adoção dos social media (MICHAELIDOU et al., 2011, p.1154).

Embora nesta área, os estudos referentes a Portugal sejam escassos, segundo o questionário conduzido pela OberCom $^{3}$ (2012), numa amostra de 450 indivíduos, 59.2\% dos inquiridos responderam que 'É importante para mim que as marcas/empresas tenham perfil nas redes sociais' (OBERCOM, 2012, p. 30). Ainda que o estudo não seja direcionado a empresas, é possível afirmar que existe uma necessidade em Portugal da presença das empresas nos social media. De forma a cativar essa ligação, torna-se necessário que as startups se tornem mais dinâmicas e recetivas a acompanhar a evolução dos social media. Para tal, deverão dar especial atenção ao conteúdo web que é partilhado com a sua audiência, de forma a cativar a sua atenção. Desta forma, partilhar imagens que mostrem a importância da marca, partilhar vídeos relacionados com a empresa, partilhar infográficos, identificar os autores de um texto/imagem/vídeo, de forma a que haja uma ligação entre o utilizador e o colaborador da empresa, ou mesmo, permitir aos utilizadores que partilhem imagens com a empresa, são possíveis abordagens para prender a atenção da audiência.

No que diz respeito ao marketing digital, a Internet ao alcançar um grande número de utilizadores conseguiu não só atrair o utilizador comum, como também atrair as empresas, que veem na rede uma forma de alcançar os seus consumidores, através de diferentes abordagens. O marketing digital, ou como também é conhecido, marketing nas redes sociais online ou web marketing, consiste num processo de marketing que possibilita às empresas a promoção de websites, produtos e/ou serviços através dos SNS, com o intuito de atingirem mais eficazmente a sua audiência, comparativamente com a utilização de canais de comunicação tradicionais (WEINBERG, 2009, p. 149 - 150).

Segundo Scott “(...) web marketing is about delivering useful content at just the precise

\footnotetext{
${ }^{3}$ OberCom (Observatório da Comunicação): http://www.obercom.pt/ Associação portuguesa sem fins lucrativos, com forte presença na investigação das redes sociais na sociedade portuguesa.
} 
moment that a buyer needs it" (SCOTT, 2010, p. 7). Desta forma, as empresas tendem a dar mais atenção às escolhas do consumidor, à sua opinião e à forma como comunicam com este, permitindo um maior engagement e também uma maior aproximação da audiência.

Em relação ao marketing digital B2B este é considerado, significativamente diferente do B2C. No negócio B2B, os produtos/serviços têm uma venda mais complexa, existe um maior risco, é necessário um maior estudo por parte dos stakeholders, e assim sendo adquirir a confiança destes é essencial, caso contrário o negócio não irá crescer. Por forma a ganhar esta confiança, as empresas B2B têm que se diferenciar, sendo necessário destacarem-se e serem diferentes das restantes. Desta forma, oferecer conteúdo com qualidade e útil para o cliente nos social media é uma das estratégias que as empresas podem adotar.

Atualmente a partilha de conteúdos online passou a integrar as rotinas de utilização dos novos media, onde uma das razões que leva os indivíduos a partilharem conteúdos é a sua utilidade (BERGER; MILKMAN, 2012, p. 192 - 193).

O marketing viral surge como uma forma de marketing onde a difusão de conteúdo web é disseminado através do eWOM e através da propagação de mensagens que tendem a ser rápidas, envolventes e contagiosas, onde um grande número de utilizadores provocado pelo conteúdo da mensagem tende a partilhá-lo influenciando e encorajando outros utilizadores a fazerem o mesmo. Os autores Andrade, Mazzon e Katz referenciam que este tipo de partilha está também relacionada com o campo psicológico das relações sociais (ANDRADE; MAZZON; KATZ, 2006, p. 8).

Segundo o estudo desenvolvido por Berger e MilkMan, sobre o que torna o conteúdo online viral, os autores concluíram que por norma o conteúdo positivo é mais viral do que o conteúdo negativo, embora o conteúdo que provoca emoções positivas ou negativas, como exaltação, raiva ou ansiedade, tenda a ser mais viral (BERGER; MILKMAN, 2012, p. 193).

Já de acordo com o estudo de Leskovec, Adamic e Huberman, a partilha do conteúdo é mais rapidamente disseminada entre indivíduos ligados por relações fortes ${ }^{4}$, entre família e

\footnotetext{
${ }^{4}$ Relações fortes (ou laços fortes) e relações fracas (ou laços fracos), implicam a duração da relação, a intensidade emocional, a intimidade, os serviços recíprocos e a pluralidade de conteúdos de troca existentes num laço (GRANOVETTER, 1973, p. 3).
} 
amigos, do que as relações fracas ${ }^{4}$, mencionando que as caraterísticas dos laços sociais, tendem a influenciar o comportamento dos restantes utilizadores (LESKOVEC; ADAMIC; HUBERMAN, 2007, p. 2 - 4).

Através destes estudos e conhecendo os hábitos dos utilizadores é possível maximizar o retorno dos conteúdos criados pelas empresas (BERGER; MILKMAN, 2012, p. 193), pois têm o conhecimento base para criar tipos de conteúdos que detenham o que é necessário para se tornarem virais.

Outra das formas de maximizar o retorno é através do Social Media Marketing (SMM). Entende-se por SMM as técnicas de marketing utilizadas para promover uma ligação entre a marca e o consumidor, tirando partido das potencialidades dos SNS, que permitem gerar comunidades de utilizadores, que se agrupam por temas, originando um conjunto de interdependências que se prolongam no tempo. Este conhecimento sobre os comportamentos e rede em que se inserem os utilizadores, permite explorar as correlações entre utilizadores, sob forma de ações de marketing viral (INESTING SEARCH, 2007b, p. 1).

Segundo o autor Weinberg, os SMM ligam prestadores de serviços, empresas e comunidades, com vastas audiências de influenciadores e consumidores, onde utilizando este novo tipo de marketing as empresas adquirem tráfego, seguidores e reconhecimento da marca (WEINBERG, 2009, p. 2).

De um modo geral, o conteúdo web é atualmente visto como qualquer tipo de dados online criados por utilizadores (quer sejam indivíduos ou empresas), designadamente texto, áudio, vídeo, gráficos, animações ou imagens, onde os social media são uma alavanca para que estes sejam publicados e partilhados, através de um acesso restrito ou público numa plataforma online, de um modo simples e eficaz. O conteúdo é assim criado, tendo como principal objetivo os consumidores, onde estes são também os agentes que sustentam as plataformas online, visto serem os maiores produtores e distribuidores de conteúdos (COSTA, 2011, p. 26 - 29).

Desta forma, o principal desafio no que diz respeito ao conteúdos web nos SNS é conseguir perceber a distribuição de qualidade existente, pois poderão surgir itens de grande qualidade, mas também poderão surgir de fraca qualidade ou mesmo abusivos. Isto torna a tarefa de filtragem e rankings nestes sistemas mais complexos do que em outros domínios (AGICHTEIN et al., 2008, p. 1). 
O conteúdo visual poderá ser um grande contributo, pois está-se a tornar cada vez mais uma das principais formas de comunicação. A aposta das empresas em partilhar conteúdo visual, como imagens e vídeos que cativam a atenção, trazem mais leitores e consumidores, o que por sua vez origina num maior retorno e engagement.

Existem agências de marketing, que têm como objetivo empresarial a criação de conteúdos web de qualidade para outras organizações, de forma a que através dessa criação de conteúdo por especialistas na área, seja possível proporcionar um maior envolvimento com a marca. Assim, através de um conteúdo mais especializado obtém-se um consumidor mais atualizado e satisfeito.

Neste âmbito, surge a criação da audiência da organização, ou seja, um conjunto de utilizadores/espetadores que prestam atenção e/ou participam e interagem num determinado tipo de comunicação. Atendendo a que a participação nos social media, de determinada marca, depende da interação entre os utilizadores, a audiência tem como função a participação através de comentários, partilhas ou consoante o social media utilizado, edição de conteúdos. Uma empresa presente nos social media sem audiência, atinge facilmente o fracasso. Desta forma, para alcançar uma vantagem competitiva mais forte, as empresas B2B indicam que os SNS são uma ferramenta importante para comunicarem com a sua audiência mais rapidamente (MICHAELIDOU et al., 2011, p. 1153 - 1154).

De forma ao comunicarem melhor com as suas audiências, as empresas tendem cada vez mais a recorrer ao content marketing. De acordo com o estudo efetuado pelo Content Marketing Institute e MarketingProfs a 1092 profissionais de marketing em agosto de 2011, o marketing de conteúdos tem ganho uma maior dinâmica (CONTENT MARKETING INSTITUTE; MARKETING PROFS, 2012, p. 8). O content marketing ou marketing de conteúdo pretende providenciar conteúdos de alta qualidade para os utilizadores, parceiros, seguidores, consumidores, de forma a que a empresa aumente a sua participação online, as suas vendas e a fidelização dos seus clientes (NELSON; GEBAUER; GEBAUER, 2012, p. 3).

De acordo com a Marketo (MARKETO, 2010, p. 2), o marketing de conteúdo deverá seguir as seguintes regras:

- Não deve ser promocional, caso contrário não irá entusiasmar ou inspirar a confiança necessária no utilizador; 
- Relevante para o destinatário, pois o conteúdo tem que ser do interesse do utilizador;

- Deve responder a um problema da empresa, pois fornecer informação sobre um tema onde não existem dúvidas, será um esforço desnecessário;

- Bem escrito, caso contrário poderá influenciar negativamente a reputação da empresa;

- Relevante para a empresa e de acordo com os objetivos desta;

- Seja possível comprovar e que as opiniões sejam imparciais.

Para que a empresa consigua cumprir as regras acima referidas deverá ter uma estratégia de comunicação bem definida, e de acordo com os objetivos da empresa, que sejam coerentes e possíveis de realizar. A estratégia de comunicação consiste no processo de definir a planificação e diretrizes a seguir no futuro.

No que diz respeito às vantagens e desvantagens da partilha de conteúdo web são diversas. Relativamente às vantagens, identificam-se as seguintes (PEREIRA, 2012, p. 5 $10)$ :

- Através da partilha de conteúdo com qualidade e assertividade é possível alcançar de uma forma mais simples e rápida o mercado-alvo, levando a audiência a envolver-se mais rapidamente com a marca e a empresa;

- Permite construir relacionamentos;

- Possibilita a melhoria dos processos de negócios;

- Com as palavras-chave no momento da partilha, é possível também melhorar a posição dos conteúdos nos motores de pesquisa;

- Facilita a venda quando surge a oportunidade;

- Com uma estratégia de comunicação adaptada à empresa é possível poupar dinheiro em publicidade ou noutras formas de marketing mais dispendiosas;

- Envolve os utilizadores e a promoção da interação entre eles;

- Aquisição de um maior engagement com a audiência.

Quanto às possíveis desvantagens que a partilha de conteúdos web pode trazer, identificam-se as seguintes:

- Proteção dos dados referentes ao conteúdo; 
- Consumo de tempo;

- Ser necessário deter conhecimentos que permitam calcular o Return On Investment e Return On Engagement.

O conceito de engagement, ou 'envolvimento com a marca', nos social media implica estabelecer um relacionamento com os utilizadores associados à página/perfil numa determinada plataforma dos novos media. Este envolvimento é avaliado através de métricas ligadas à quantidade de vezes que o público participa, comenta e se mobiliza em torno da presença online de determinada marca. Por exemplo, no Facebook a medição do engagement poderá ser calculada, dividindo a totalidade de 'likes' e comentários, pelo número total de fãs da página (MARKETO, 2012, p. 5).

No que diz respeito ao Return On Investment (ROI) não é mais do que "o beneficio financeiro obtido em relação ao custo da campanha de publicidade" (INESTING SEARCH, 2007a, p. 1). Esta é uma medida de desempenho e uma fórmula padrão, que não sendo simples de medir de uma perspectiva $\mathrm{B} 2 \mathrm{~B}$, na área dos social media, não é impossível, embora a empresa necessite de ter uma ideia clara de quais são os seus objetivos. Segundo Oliveira, Carvalho e Wright, o ROI é "calculado para medir o desempenho de um investimento em relação a outro investimento", sendo expresso em percentagem e baseado em retornos durante um período de tempo (OLIVEIRA; CARVALHO; WRIGHT, 2012, p. 12). O ROI surge como uma ajuda para a empresa compreender melhor o seu público-alvo, mas principalmente para averiguar se de facto o investimento inicial aplicado nos social media, gerou um retorno positivo, pois em caso afirmativo, implica uma melhoria na relação consumidor-produto (OLIVEIRA et al., 2012, p. 13).

Em Portugal pouco se sabe quanto à medição pelas empresas do ROI, mas um estudo internacional da Mzinga and Babson Executive Education, analisado pela eMarketer, datado de setembro de 2009 e com uma amostra de 555 participantes nas áreas profissionais de media, finanças, consultoria, marketing, recursos humanos, engenharia, entre outros, identifica que $84 \%$ das empresas não medem o ROI (MZINGA AND BABSON EXECUTIVE EDUCATION, 2009, p. 1; RAMSEY, 2010).

Alguns autores defendem que não é possível aplicar o ROI nos social media, pois estes estão relacionados com a interatividade humana e com a sua comunicação, e não com algo 
que pode ser traduzido em números, isto é, não é quantificável. Surge assim o conceito de Return On Engagement (ROE), isto é, o retorno do envolvimento com a marca, onde este irá avaliar e medir o envolvimento dos consumidores com a empresa na web (WIGMO; WIKSTRÖM, 2010, p. 14 - 15).

"ROE can be used to measure the company's social profit, the dialog that in the end will increase the company's economic profit, the ROI. Better ROE can be stretched towards better ROI, and can be used to predict the company's future" (NÜÜD, 2009, apud WIGMO; WIKSTRÖM, 2010, p. $15)$.

Desta forma, o ROE encontra-se vinculado à ligação existente entre a marca presente nos social media, a sua audiência e a avaliação que a empresa pode efetuar de forma a calcular o nível de compromisso e reciprocidade existente entre os dois. Sem envolvimento entre a audiência e a marca, a presença da empresa nos social media falha.

Para conseguir medir o ROE é necessário alcançar um compromisso com a audiência, captar a sua confiança e criar objetivos concretizáveis. De acordo com Wetzel, o engagement é a nova consciência e o ROE é o novo ROI. A autora refere que o ROE tem uma abordagem mais centralizada no cliente, no exterior e está mais direcionado para a interação entre os indivíduos, ao contrário do ROI. Através do ROE é possível medir a velocidade a que a mensagem chega à audiência; a viralidade, isto é, a frequência que determinada mensagem passa de consumidor em consumidor; e a veracidade, o nível de verdade que é mantido enquanto a mensagem se espalha (WETZEL, 2008, p. 1).

Já o conceito de Social Media Optimization (SMO) foi referenciado pela primeira vez por Bhargava em 2006, onde o autor menciona que SMO refere-se à implementação de alterações para optimizar um site, para que seja mais facilmente mencionado em pesquisas de social media, como é o caso do Technorati ${ }^{5}$ e que sejam incluídos mais frequentemente em posts de blogs, podcasts ou vlogs (vídeo blogs) (BHARGAVA, 2006, p. 1).

Segundo Fichter, após a criação da estratégia de comunicação e do conteúdo web para os social media, é necessário analisar se o método utilizado está a obter retorno (FICHTER, 2007, p. 58 - 59). Os Social Media Optimization (SMO) são um conjunto de procedimentos para analisar e compreender a audiência relativamente ao conteúdo web

\footnotetext{
${ }^{5}$ Technorati: http://technorati.com/ 
partilhado em determinada plataforma de social media, de forma a converter essa atividade em tráfego para o site da empresa.

Desta forma existem duas definições de SMO, a optimização para os social media, e a optimização dos social media. A primeira refere-se à definição de Bhargava, onde o objetivo é tornar o site mais amigável às condutas da audiência nos social media, enquanto que a segunda, refere-se à definição de Fichter, isto é, a utilização dos social media e a compreensão do fluxo de informação para a promoção de conteúdo web (CASTRO, 2011, p. 1 - 83).

Segundo Fichter, após definir os objetivos do SMO é necessário medir o engagement dos seguidores e avaliar as atividades destes, pois a análise de "page views" e visitantes não é suficiente (FICHTER, 2007, p. 58). O principal objetivo do SMO é gerar a divulgação de determinado conteúdo web, por forma a aumentar o conhecimento da audiência de determinado produto ou serviço. O SMO é em parte semelhante ao Search Engine Optimization (SEO), pois em ambos o objetivo é gerar tráfico e encaminhar a audiência para determinado site.

Seguidamente apresenta-se a metodologia de análise da presença de startups portuguesas nos social media.

\section{METODOLOGIA}

A metodologia de investigação utilizada assenta inicialmente numa observação direta da atividade de 106 startups portuguesas, nas áreas de negócio das TIC, Media e Design, nos social media. No decurso da investigação foi realizada uma análise às startups que se encontram na Incubadora da Universidade de Aveiro, no Instituto Pedro Nunes da Universidade de Coimbra, no Taguspark do Instituto Superior Técnico, na Startup Lisboa, no Madan Parque da Universidade Nova de Lisboa e no UPTEC da Universidade do Porto, de forma a proporcionar uma maior familiaridade com estas empresas e as suas respetivas estratégias de comunicação. No fim desta análise, selecionaram-se 15 startups mais dinâmicas e ativas nos social media (ver figuras 1, 2, 3, 4 e 5), de acordo com a sua atividade entre 31 de outubro de 2012 e 8 de novembro de 2012.

A realização da análise foi efetuada, tendo em conta as principais plataformas de social media, nomeadamente, Facebook, Twitter, Linkedin, Google+, Youtube, Vimeo, Pinterest e Myspace, no que diz respeito à partilha de conteúdo web e à frequência de utilização de 
cada empresa, tal como, a utilização de blog e a existência de análises estatísticas através do Google Analytics na página institucional de cada startup em análise. De seguida, procedeu-se à análise da dinâmica das startups nos social media, onde foram selecionadas as 15 consideradas mais ativas, levando em conta o tipo de conteúdo partilhado, tendo este sido analisado a partir da subdivisão de três grupos: multimédia (imagens, vídeo ou áudio), status (apenas texto) e partilha de ligações. $\mathrm{Na}$ análise efetuada, a metodologia adotada foi "muito frequente" e "frequente" para os casos onde no espaço de tempo da análise foram divulgadas entre três ou mais partilhas de conteúdos, "raramente" e "muito raramente" para os casos onde no espaço de tempo da análise foram divulgadas entre uma a duas partilhas de conteúdos e "nunca" para os casos onde no espaço de tempo da análise não foram divulgadas partilhas de conteúdos (ver Legenda 1).

Legenda:

Muito Frequente
Frequente
Raramente
Muito Raramente
Nunca

Legenda 1: Legenda adotada na análise da dinâmica nos social media, das 15 startups.

\section{ANÁLISE DE RESULTADOS}

Analisando aprofundadamente as 15 startups selecionadas, pode-se concluir que no que diz respeito ao Facebook afirma-se rapidamente que todas as startups analisadas têm página neste SNS (Figura 1). Em geral a partilha de status é a menos comum, onde 12 das 15 empresas "nunca" ou "muito raramente" partilham apenas texto e, a partilha de conteúdo multimédia é o mais recorrente onde 9 das 15 empresas, partilha este tipo de conteúdo "muito frequentemente". 


\begin{tabular}{|c|c|c|c|c|c|c|c|c|c|c|c|}
\hline \multicolumn{12}{|c|}{$\begin{array}{l}\text { FACEBOOK } \\
\text { (analiso efetuada no dia } 15 \text { do novembro de 2012) }\end{array}$} \\
\hline \multirow{2}{*}{ Emprosa } & \multirow{2}{*}{ Pagina } & \multicolumn{3}{|c|}{ Tipo do Conteúdo } & \multirow{2}{*}{$\begin{array}{c}\text { Partilha do conteúdo } \\
\text { rolacionado com a } \\
\text { empresa }\end{array}$} & \multirow{2}{*}{$\begin{array}{l}\text { Media de likes } \\
\text { o comentários } \\
\text { por post }\end{array}$} & \multirow{2}{*}{$\begin{array}{l}\text { Respondo a } \\
\text { comentários dos } \\
\text { utilizadores }\end{array}$} & \multirow{2}{*}{ Likes } & \multirow{2}{*}{$\begin{array}{c}\text { Lingua em que } \\
\text { se encontram os } \\
\text { conteuddos }\end{array}$} & \multirow{2}{*}{$\begin{array}{l}\text { Última } \\
\text { atualizaçăo }\end{array}$} & \multirow{2}{*}{$\begin{array}{l}\text { Data do } \\
\text { adesdo }\end{array}$} \\
\hline & & Multimodia & Status & $\begin{array}{l}\text { Partilha do } \\
\text { ligaçळos }\end{array}$ & & & & & & & \\
\hline Startup A & Sim & - & - & - & - & 3 & - & 412 & EN & $14 / 11 / 2012$ & 8/11/2011 \\
\hline Startup 8 & Sim & - & - & - & - & 3 & - & 69 & PT & 14/11/2012 & 30322011 \\
\hline Startup C & Sim & - & $\bullet$ & - & - & 5 & - & 475 & PTOEN & 15/11/2012 & $28.01 / 2010$ \\
\hline Startup D & Sim & - & - & - & - & 20 & • & 6.388 & PT EEN & $5 / 11 / 2012$ & $1201 / 2011$ \\
\hline Startup E & Sim & - & $\bullet$ & - & - & 1 & - & 159 & PT EEN & $29 / 10 / 2012$ & 9/02/2012 \\
\hline Startup $F$ & Sim & - & - & - & - & $\mathbf{5}$ & - & 12.642 & PT & 15/11/2012 & $01 / 2012$ \\
\hline Startup G & Sim & - & $\bullet$ & - & - & 10 & - & 662 & PT & 19/10/2012 & 4/03/2012 \\
\hline Startup $\mathrm{H}$ & Sim & - & - & - & - & 5 & - & 212 & EN & 15/11/2012 & $21 / 03 / 2011$ \\
\hline Startup 1 & Sim & - & $\bullet$ & - & - & 2 & $\bullet$ & 237 & PTEEN & $15 / 11 / 2012$ & $29.06 / 2010$ \\
\hline Startup J & Sim & - & - & - & - & 10 & - & 678 & PT EEN & 15/11/2012 & $27 / 01 / 2010$ \\
\hline Startup $\mathrm{K}$ & Sim & - & $\bullet$ & - & - & 3 & - & 902 & PT & 15/11/2012 & $25,05 / 2010$ \\
\hline Startup L & Sim & - & - & - & - & 3 & - & 229 & EN & 14/11/2012 & 2008 \\
\hline Startup M & Sim & - & $\bullet$ & - & - & 1 & - & 72 & PT $O E N$ & $8 / 11 / 2012$ & $14 / 11 / 2009$ \\
\hline
\end{tabular}

Figura 1: Análise da dinâmica no Facebook nas 15 startups.

Comparando as 15 startups conclui-se que a Startup D é a mais dinâmica no Facebook, sendo a que tem a média mais elevada de likes ou comentários de utilizadores por post partilhado e a segunda com um maior número de likes à página. O tipo de conteúdo mais utilizado é a partilha de ligações, nomeadamente links para páginas de clientes, onde se pode visualizar produtos/serviços desenvolvidos pela empresa, links para portais de comunicação com notícias relacionadas com a empresa, links para a página institucional da empresa, entre outros. De seguida, é a partilha de conteúdo multimédia o mais partilhado, sendo este maioritariamente constituído por imagens referentes a notícias da empresa. É de referir que, embora a Startup $D$ seja a empresa com uma média de likes e comentários mais elevada, não permite comentários espontâneos dos utilizadores, apenas mensagens privadas. A Startup B é exemplo contrário, que além de permitir a partilha de comentários, imagens ou vídeos, permite ainda recomendações à empresa.

Em relação à partilha de conteúdo relacionado exclusivamente com produtos ou serviços da empresa, 6 das 15 startups encontram-se neste grupo, enquanto que as restantes não partilham qualquer conteúdo ou partilham conteúdo que não está relacionado diretamente com a startup, como é o caso da Startup J. Na página da Startup J é usual partilhar imagens dos colaboradores da empresa e notícias (que não estão ligadas diretamente à empresa).

Quanto à língua em que são partilhados os conteúdos, apenas 4 das 15 empresas, o fazem exclusivamente em português. As restantes partilham conteúdo em inglês e português ou exclusivamente em inglês.

Em relação ao Twitter (Figura 2), 5 das 15 startups não têm perfil criado nesta 
plataforma, onde a Startup E consegue ser a mais dinâmica neste microblog, sendo a única que "muito frequentemente" responde aos comentários dos seus seguidores, que mantém uma interação com estes e que possui um maior número de seguidores.

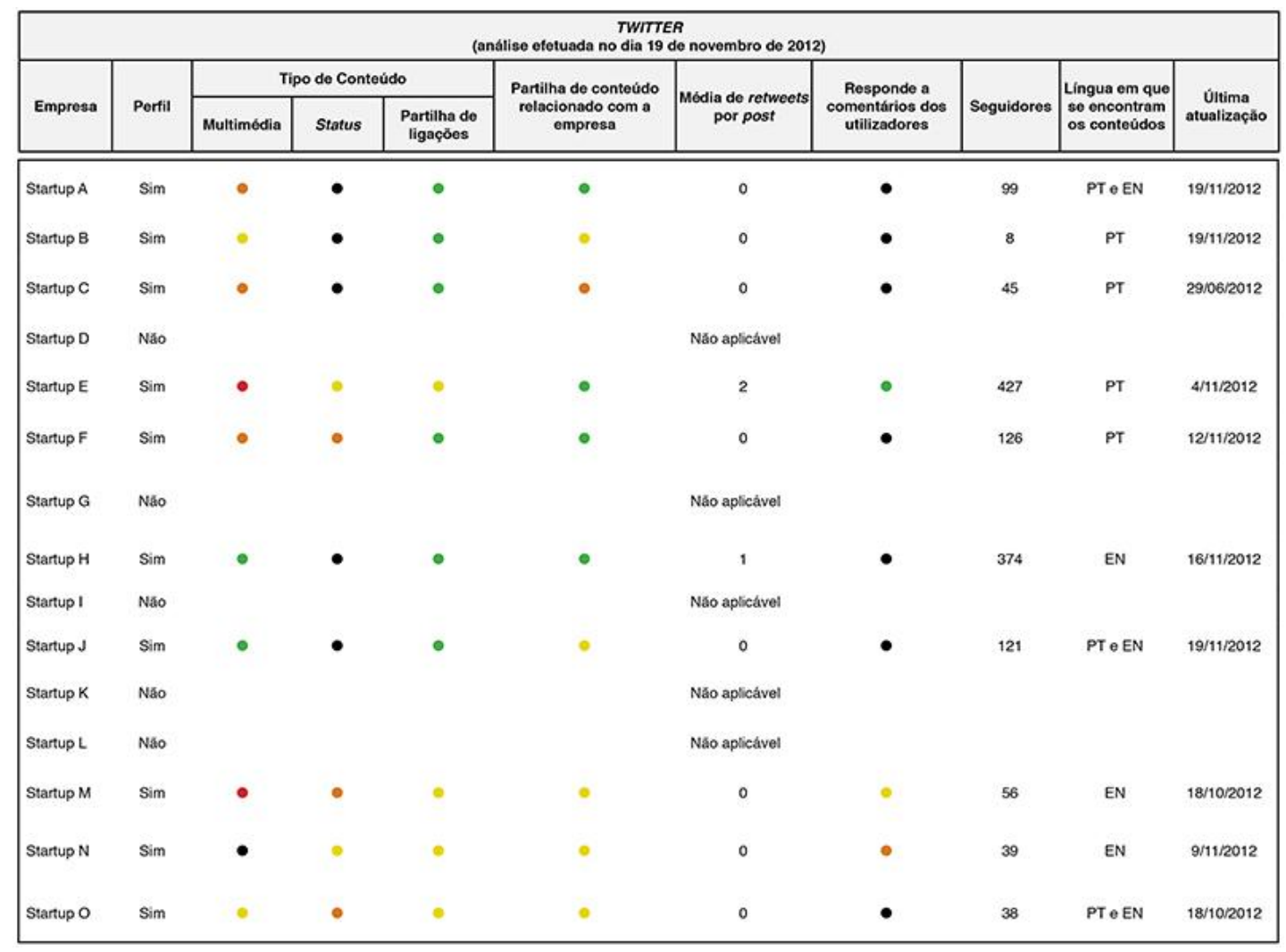

Figura 2: Análise da dinâmica no Twitter das 15 startups.

No Twitter a partilha de ligações é visivelmente mais frequente do que a partilha de conteúdos multimédia e ainda mais, em relação à partilha de status/texto. Quanto à interação com os seguidores, apenas 3 das empresas analisadas é que respondem a comentários, revelando que esta plataforma encontra-se subaproveitada.

Quanto ao Linkedin (Figura 3), a presença neste SNS é ainda mais diminuta. Embora, apenas 4 das 15 empresas analisadas não tenham um perfil nesta rede, a dinâmica das restantes é muito reduzida. Ainda assim, a Startup $C$ é a que mais sobressai desta análise, tendo no entanto uma partilha de conteúdos multimédia e de ligações, respetivamente, "muito rara" e "rara" e partilha de status "frequente". Nenhuma das empresas tem grupos relacionados, o que implica que a interação com os seguidores seja também baixa. 


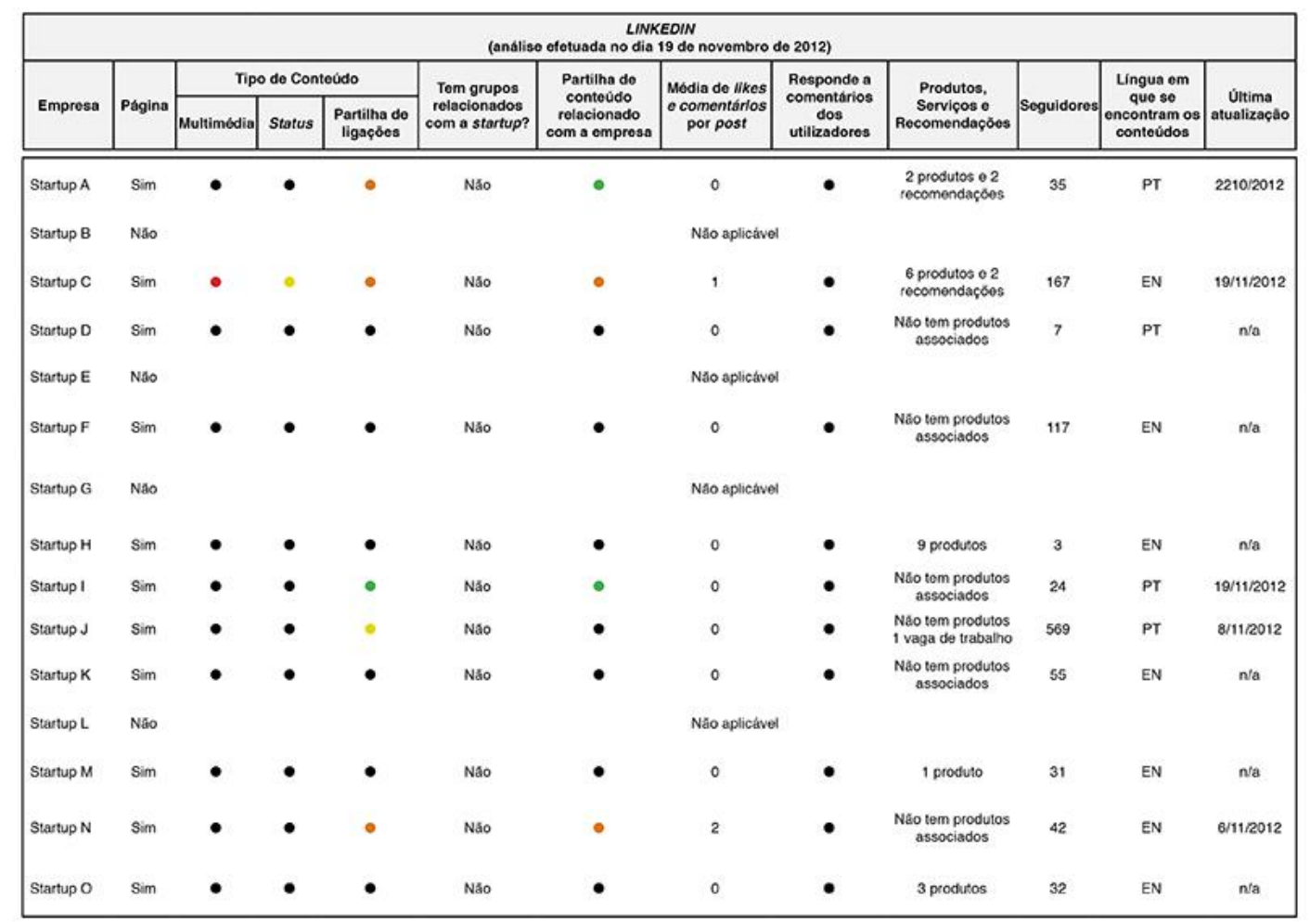

Figura 3: Análise da dinâmica no Linkedin das 15 startups.

No que diz respeito ao Google+ (Figura 4), 7 das 15 startups não está presente neste SNS. A Startup D, comparando com as restantes, é uma das mais ativas, partilhado "muito frequentemente" links, onde o conteúdo é por norma relacionado com a empresa. Contudo, não efetua partilhas desde 1 de maio de 2012. A Startup $F$ é outra das empresas que "muito frequentemente" partilha ligações para a sua página institucional neste SNS e frequentemente partilha ligações multimédia, embora a interação empresa e seguidores, seja muito reduzida. 


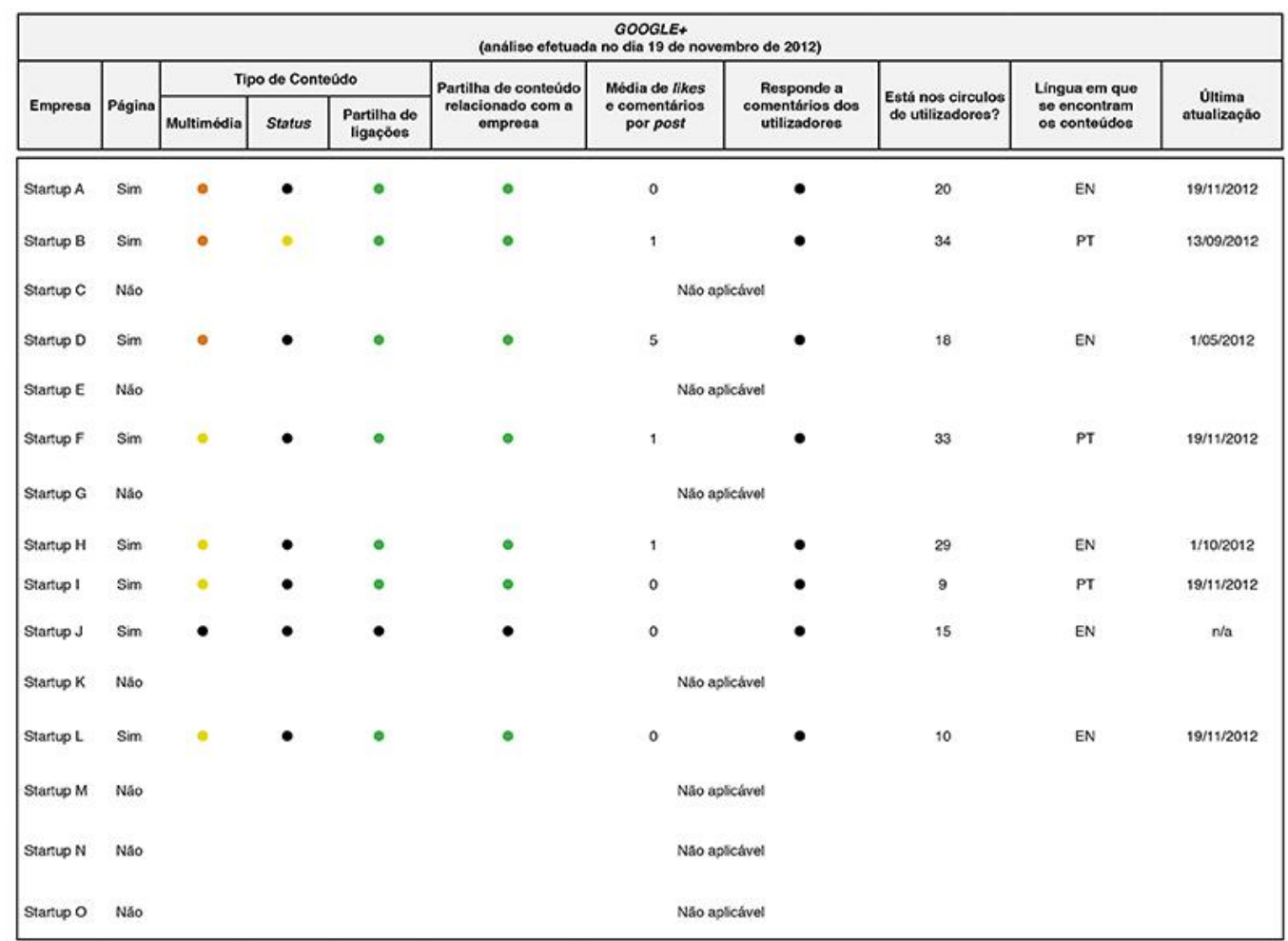

Figura 4: Análise da dinâmica no Google+ das 15 startups.

Quanto ao Youtube e Vimeo (Figura 5), apenas 5 das 15 empresas não se encontra em nenhum destes SNS. Embora todas partilhem vídeos relacionados com a empresa, a interação entre startup e seguidores é muito reduzida ou praticamente nula, onde a grande maioria dos vídeos é posteriormente partilhado num outro SNS, sendo o mais comum o Facebook. 


\begin{tabular}{|c|c|c|c|c|c|c|c|c|c|c|}
\hline \multicolumn{11}{|c|}{$\begin{array}{l}\text { Youtube o Vimeo } \\
\text { (analiso ofotuada no dia } 1 \text { do dozombro de 2012) }\end{array}$} \\
\hline Empresa & Canal & $\begin{array}{c}\text { Numero } \\
\text { de vidoos } \\
\text { partilihados }\end{array}$ & $\begin{array}{l}\text { Número de } \\
\text { subscritores }\end{array}$ & $\begin{array}{l}\text { Visualizaçঠes } \\
\text { dos vidoos }\end{array}$ & $\begin{array}{l}\text { Partilha do conteúdo } \\
\text { relacionado com a } \\
\text { omprosa? }\end{array}$ & $\begin{array}{l}\text { Media de likes } \\
\text { - comentatios } \\
\text { por vidoo }\end{array}$ & $\begin{array}{c}\text { Rospondo a } \\
\text { comentarios dos } \\
\text { utilizadoroos }\end{array}$ & $\begin{array}{l}\text { Lingua om que } \\
\text { so encontram } \\
\text { os contoưdos }\end{array}$ & $\begin{array}{l}\text { Data do } \\
\text { adosăo }\end{array}$ & $\begin{array}{l}\text { Última } \\
\text { atualizaçăo }\end{array}$ \\
\hline \multirow{2}{*}{ Stantup A } & Youtube & 97 & 59 & 171.834 & - & 1 & - & EN & $28 / 09 / 2009$ & 26/11/2012 \\
\hline & Vimeo & 2 & n/a & n/a & - & 0 & Na & PT $E$ EN & $24 / 11 / 2011$ & 10/01/2012 \\
\hline Startup B & Youtube & 3 & 2 & 1.088 & - & 0 & $\mathrm{~N} / \mathrm{a}$ & PT & $14 / 05 / 2008$ & 20102/2012 \\
\hline \multirow{2}{*}{ Stantup C } & Youtube & 27 & 43 & 110.831 & - & 1 & - & PT $E$ EN & $02 / 09 / 2008$ & $27 / 09 / 2012$ \\
\hline & Vimeo & 13 & naa & n/a & - & 2 & - & PT EEN & 02/09/2008 & 10/10/2012 \\
\hline Startup D & Nâo & \multicolumn{9}{|c|}{ Nâo aplicável } \\
\hline Startup E & Nå & \multicolumn{9}{|c|}{ Năo aplichivol } \\
\hline Startup $F$ & Youtubo & 1 & 0 & 633 & - & 2 & $n / a$ & EN & n/a & $27 / 04 / 2012$ \\
\hline Startup G & Vimos & 5 & 8 & n/a & - & 2 & náa & PT $\in$ EN & $06 / 09 / 2012$ & 17/10/2012 \\
\hline \multirow{2}{*}{ Startup $\mathrm{H}$} & Youtube & 7 & 9 & 1.647 & - & 1 & n/a & EN & 05/01/2012 & 01/10/2012 \\
\hline & Vimeo & 20 & 10 & n/a & - & 2 & - & EN & $24 / 09 / 2010$ & $15 / 08 / 2012$ \\
\hline Startup I & Youtube & 15 & 1 & 508 & - & 0 & $n / a$ & PT & $22 / 03 / 2012$ & 28/09/2012 \\
\hline Startup J & Youtube & 7 & 43 & 7.478 & - & 3 & - & PT & $20107 / 2012$ & 19/11/2012 \\
\hline Startup K & Nåo & \multicolumn{9}{|c|}{ Năo aplicável } \\
\hline Startup L & Youtubo & 3 & 1 & 93 & - & 0 & ra & EN & $09 / 05 / 2012$ & $23 / 11 / 2012$ \\
\hline Stantup M & Youtube & 1 & 0 & 65 & - & 0 & n/a & PT & 29/11/2010 & 29/11/2010 \\
\hline Startup N & Nåo & \multicolumn{9}{|c|}{ Năo aplicável } \\
\hline Startup O & Năo & \multicolumn{9}{|c|}{ Nấo aplicável } \\
\hline
\end{tabular}

Figura 5: Análise da dinâmica no Youtube e Vimeo das 15 startups.

\section{CONSIDERAÇÕES}

Após a análise efetuada verificou-se que as startups portuguesas analisadas têm uma participação muito reduzida nos social media, onde a grande maioria tem página no Facebook, com uma atividade relativamente baixa, existindo na maior parte, uma lacuna na qualidade e quantidade de conteúdos web que estas empresas partilham com a sua audiência. A análise efetuada parece contrariar a ideia de que empresas nestes domínios de atuação, em caso de mudanças na área das tecnologias de comunicação e informação, iriam ser as que mais facilmente se adaptariam (MICHAELIDOU et al., 2011, p. 1155) e integrariam nas suas práticas novas plataformas de interação. Contudo, considera-se que para alcançar uma conclusão válida é necessário prosseguir com a investigação. Neste sentido, irá proceder-se à aplicação de um inquérito por questionário, dirigido a 6 das 15 startups previamente selecionadas na primeira fase desta investigação, com o intuito de adquirir um maior conhecimento do seu comportamento nos social media e suas respetivas estratégias de comunicação. 
Por forma a produzir conclusões válidas e com aplicabilidade, a terceira etapa do processo de investigação envolverá a definição de uma proposta (teórica), criada e validada em parceria com as startups selecionadas para o estudo, com o intuito de estabelecer um modelo capaz de constituir uma alavancagem para uma presença dinâmica e geradora de mais-valia nos social media.

Após a análise dos dados do inquérito por questionário será desenvolvida, em conjunto com as startups alvo de estudo, a proposta do modelo de gestão de conteúdo, referido anteriormente. Esta proposta será efetuada tendo por base a análise dos dados adquiridos no inquérito, e terá o acompanhamento e validação das startups envolvidas no estudo.

\section{REFERÊNCIAS}

AGICHTEIN, E. et al. Finding high-quality content in social media. Proceedings of the international conference on Web search and web data mining, 2008. Palo Alto, California, USA. ACM. p.183-194.

ALEJANDRO, V.; NORMAN, A. G. Manual introdutório à análise de Redes Sociais. UAEM-Universidad Autonoma Del Estado de Mexico, 2005.

ANDRADE, J.; MAZZON, J. A.; KATZ, S. Boca-a-boca eletrônico: explorando e integrando conceitos de marketing viral, buzz marketing e word-of-mouse. $30^{\circ}$ Encontro da ANPAD. ANPAD. Brasil. II 2006.

ANVIL MEDIA INC. SEM Glossary of Terms. 2010. Disponível em: < http://www.anvilmediainc.com/search-engine-marketing-resources/search-enginemarketing-glossary >. Acesso em: 17 out. 2012.

BERGER, J.; MILKMAN, K. What Makes Online Content Viral? Journal of Marketing Research (JMR), v. 49, n. 2, p. 192-205, 2012. ISSN 00222437. Disponível em: < http://search.ebscohost.com/login.aspx?direct=true \&db=bth\&AN=74279106\&site=ehostlive >. Acesso em: 02 nov. 2012.

BERTHON, P. R. et al. Marketing meets Web 2.0, social media, and creative consumers: Implications for international marketing strategy. Business Horizons, v. 55, n. 3, p. 261271, 2012. ISSN 0007-6813. Disponível em: < http://www.sciencedirect.com/science/article/pii/S0007681312000080 >. Acesso em: 02 nov. 2012.

BHARGAVA, R. 5 Rules of Social Media Optimization (SMO). 2006. Disponível em: < http://www.rohitbhargava.com/2006/08/5_rules_of_soci.html >. Acesso em: 23 dez. 2012. 
CARVALHO, R. J. R. D. Branding para micro e pequenas empresas. 2010. $148 \mathrm{f}$. Dissertação (Mestre em Marketing). Faculdade de Economia, Universidade do Algarve, Universidade do Algarve.

CASTRO, I. Social Media Optimization. Slideshare, 2011. Disponível em: < http://www.slideshare.net/iancsouza/social-media-optimization >. Acesso em: $23 \mathrm{dec}$. 2012.

CONTENT MARKETING INSTITUTE; MARKETING PROFS. B2B Content Marketing: 2012 Benchmarks, Budgets \& Trends. Content marketing Institute, 2012. Disponível em: $<$ http://www.contentmarketinginstitute.com/wpcontent/uploads/2011/12/B2B_Content_Marketing_2012.pdf >. Acesso em: 24 out. 2012.

COSTA, J. A. P. A. C. Estratégias de promoção de uma PME através de redes sociais. 2011. 152 f. (Master). Departamento de Comunicação e Arte, Universidade de Aveiro, Universidade de Aveiro.

FICHTER, D. How social is your web site? Top five tips for social media optimization. ONLINE - WESTON THEN WILTON, v. 31, n. 3, p. 57, 2007. ISSN 0146-5422. Disponível em: < http://connection.ebscohost.com/c/articles/24982003/how-social-yourweb-site-top-five-tips-social-media-optimization $>$.

GRANOVETTER, M. The strength of weak ties. American journal of sociology, v. 78, n. 6, p. 1360-1380, 1973. ISSN 0002-9602.

INESTING SEARCH. Retorno do Investimento (ROI). Inesting Search, 2007a. Disponível em: < http://www.inesting-search.com/recursos/glossario/roi.html >. Acesso em: 16 out. 2012.

Social Media Marketing (SMM). Inesting Search, 2007b. Disponível em: < http://www.inesting-search.com/SMM/social-media-marketing.html >. Acesso em: 16 out. 2012.

JANSEN, B. J. et al. Twitter power: Tweets as electronic word of mouth. Journal of the American Society for Information Science, v. 60, n. 11, p. 2169-2188, nov. 20092009.

JUSSILA, J. J.; KARKKAINEN, H.; LEINO, M. Benefits of social media in business-tobusiness customer interface in innovation. MindTrek '11 - Proceedings of the 15th International Academic MindTrek Conference: Envisioning Future Media Environments, 2011. Tampere, Finland. ACM, New York, NY, USA. p.167-174.

KAPLAN, A. M.; HAENLEIN, M. Users of the world, unite! The challenges and opportunities of Social Media. Business Horizons, v. 53, n. 1, p. 59-68, 2010. ISSN $0007-$ 6813.

Disponível em: http://www.sciencedirect.com/science/article/pii/S0007681309001232 >. Acesso em: 02 dec. 2012. 
KARKKAINEN, H.; JUSSILA, J.; VAISANEN, J. Social Media Use and Potential in Business-to-Business Companies' Innovation. MindTrek '10 - Proceedings of the 14th International Academic MindTrek Conference: Envisioning Future Media Environments, 2010. Tampere, Finland. ACM New York, NY, USA. p.228-236.

LESKOVEC, J.; ADAMIC, L. A.; HUBERMAN, B. A. The dynamics of viral marketing. ACM Transactions on the Web (TWEB), v. 1, n. 1, p. 5, 2007. ISSN 1559-1131.

MARKETO. Creating content that sells: Content marketing on demand generation. 2010. Disponível em: < http://docs.cdn.marketo.com/creatingContent.pdf >. Acesso em: $22 \mathrm{dec}$. 2012.

How to Optimize Social Channels for Lead Generation. 2012. Disponível em: < http://www.marketo.com/b2b-marketing-resources/best-practices/how-to-optimize-yoursocial-channels-for-lead-generation.php >. Acesso em: 22 dec. 2012.

MICHAELIDOU, N.; SIAMAGKA, N. T.; CHRISTODOULIDES, G. Usage, barriers and measurement of social media marketing: An exploratory investigation of small and medium B2B brands. Industrial Marketing Management, v. 40, n. 7, p. 1153-1159, 2011. ISSN 0019-8501. Disponível em: http://www.sciencedirect.com/science/article/pii/S0019850111001374 >.

MOTA, I. R. G. Impacto das acções implementadas no facebook para o envolvimento entre utilizadores e as marcas. 2011. Dissertação (Mestrado). Instituto Superior de Economia e Gestão, Universidade Técnica de Lisboa

MZINGA AND BABSON EXECUTIVE EDUCATION. Survey: Social Software in Business. 2009. Disponível em: < http://www.slideshare.net/PingElizabeth/survey-socialsoftware-in-business >. Acesso em: 24 out. 2012.

NELSON, E.; GEBAUER, S.; GEBAUER, J. The Social Media Way of Life for B2B Experts and Content Marketers. 2012. Disponível em: < https://exploreb2b.com/en/content-marketing-whitepaper >. Acesso em: 25 out. 2012.

NÜÜD, D. Return of Engagement - ROI:s högra hand., Mindpark, 2009. Disponível em: < http://mindpark.se/return-of-engagement-rois-hogra-hand/ >. Acesso em: 27 dec. 2012.

O'REILLY, T. What is Web 2.0: Design Patterns and Business Models for the Next Generation of Software International Journal of Digital Economics, v. 1, n. 65, p. 17-37, 2007. Disponível em: < http://ssrn.com/abstract=1008839 >. Acesso em: 20 nov. 2012.

OBERCOM. A Internet em Portugal A Sociedade em Rede, mai. 2012 2012. ISSN 21826722. Disponível em: < http://www.obercom.pt >. Acesso em: 26 nov. 2012.

OLIVEIRA, L. G. S. D.; CARVAlHO, D. E. D.; WRIGHT, J. T. C. ROI in Social Media. $9^{\circ}$ CONTECSI - International Conference on Information Systems and Technology Management. TECSI - Laboratório de Tecnologia e Sistemas de Informação FEA USP, São Paulo, Brasil: TECSI 2012. 
PEREIRA, J. M. Marketing nas Redes Sociais. Estratégia de marketing nas redes sociais - Formação eLearing. Universidade de Aveiro: UNAVE, Universidade de Aveiro 2012.

RAMSEY, G. Seven Guidelines for Achieving ROI from social media., eMarketer, 2010. Disponível em: < http://pt.scribd.com/doc/48228865/eMarketer-Social-Media-ROI >. Acesso em: 17 out. 2012.

RODRIGUEZ, M.; PETERSON, R. M.; KRISHNAN, V. Social Media's Influence on Business-To-Business Sales Performance. Journal of Personal Selling \& Sales Management, v. 32, n. 2, p. 365-378, Summer 2012 2012. ISSN 0885-3134 (print) / ISSN 1557-7813 (online). Disponível em: < http://search.ebscohost.com/login.aspx?direct=true \&db=bth\&AN=78110794\&site=ehostlive >. Acesso em: 29 nov. 2012.

SCOTT, D. M. The new rules of marketing \& PR - how to use social media, blogs, new releases, online video, and viral marketing to reach buyers directly. $2^{\mathrm{a}}$ edição. New Jersey, USA: 2010. 304 ISBN 9780470606636.

SOUSA, L. M. M. D.; AZEVEDO, L. E. O Uso de Mídias Sociais nas Empresas: Adequação para Cultura, Identidade e Públicos. IX Congresso de Ciências da Comunicação na Região Norte. Rio Branco, Brasil: Intercom - Sociedade Brasileira de Estudos Interdisciplinares da Comunicação 2010.

SOUZA, I. C. N. D.; GOMES, R. E. Desvendando as Redes Sociais: O papel das redes sociais como ferramenta da publicidade na web. XV Congresso de Ciências da Comunicação na Região Sudeste. Vitória, Brasil: Intercom - Sociedade Brasileira de Estudos Interdisciplinares da Comunicação 2010.

WEINBERG, T. The new community rules: Marketing on the Social Web. USA: O'Reilly Media, Inc., 2009. 370 ISBN 9781449379285.

WETZEL, D. Why ROE Should Be Your New ROI. Brandweek, 2008. Disponível em: $<$

http://search.ebscohost.com/login.aspx?direct=true \&db=a9h\&AN=35178823\&site=ehostlive >. Acesso em: 23 dec. 2012.

WIGMO, J.; WIKSTRÖM, E. Social Media Marketing : What role can social media play as a marketing tool? 2010. $65 \mathrm{f}$. Thesis (Bachelor). Information logistics, Växjö University, School of Mathematics and Systems Engineering

ZHANG, M.; JANSEN, B. J.; CHOWDHURY, A. Business engagement on Twitter: a path analysis. Electron Markets, v. 21, n. 3, p. 161-175, 2011. ISSN 1019-6781. Acesso em: 30 out. 2012. 
Original recebido em: 27/02/2013

Aceito para publicação em: Novembro de 2013

Ana Sofia Castilho

Licenciada desde 2006 em Tecnologias de Informação e Comunicação pela Universidade de Aveiro (Portugal), encontra-se atualmente a frequentar o Mestrado em Comunicação Multimédia pela mesma universidade, desde 2012.

Maria João Antunes

Licenciada em Novas Tecnologias da Comunicação (1998) e doutorada em Ciências e

Tecnologias da Comunicação na Universidade de Aveiro, Portugal. É docente do Departamento de Comunicação e Arte da Universidade de Aveiro e investigadora da unidade de investigação CETAC.MEDIA (Universidade de Aveiro/Universidade do Porto). 